\title{
Mechanism and Origins of Stereoselectivity in the Cinchona Thiourea- and Squaramide-Catalyzed Asymmetric Michael Addition of Nitroalkanes to Enones
}

\author{
Matthew N. Grayson*๑ \\ Centre for Molecular Informatics, Department of Chemistry, University of Cambridge, Lensfield Road, Cambridge CB2 1EW, United \\ Kingdom
}

\section{Supporting Information}

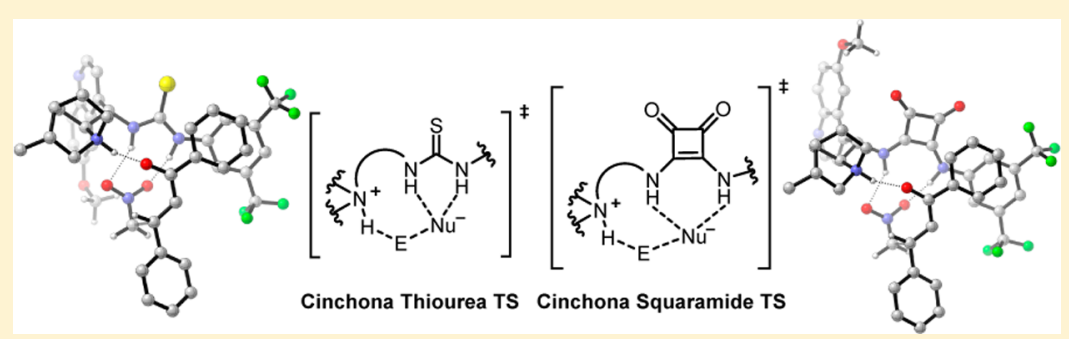

ABSTRACT: We report density functional theory calculations that examine the mechanism and origins of stereoselectivity of Soós' landmark discovery from 2005 that cinchona thioureas catalyze the asymmetric Michael addition of nitroalkanes to enones. We show that the electrophile is activated by the catalyst's protonated amine and that the nucleophile binds to the thiourea moiety by hydrogen bonding. These results lead to the correction of published mechanistic work which did not consider this activation mode. We have also investigated the corresponding cinchona squaramide-catalyzed reaction and found that it proceeds by the same mechanism despite the differences in the geometry of the two catalysts' hydrogen-bond-donating groups, which demonstrates the generality of this mechanistic model.

\section{INTRODUCTION}

Cinchona alkaloids and their derivatives have been used extensively in organic synthesis. ${ }^{1-4}$ The cinchona alkaloidderived thiourea catalysts, independently reported by the Chen, ${ }^{5}$ Soós, ${ }^{6}$ Connon, ${ }^{7}$ and Dixon ${ }^{8}$ groups in 2005 , represent one of the most important discoveries in this field of catalysis. Cinchona thioureas have since been shown to promote a wide range of highly asymmetric carbon-carbon and carbon-heteroatom bond-forming reactions ${ }^{2,9,10}$ with applications in total synthesis. $^{11}$

Soós' landmark reaction from 2005, the cinchona thioureacatalyzed asymmetric Michael addition of nitroalkanes to enones (Scheme 1), ${ }^{6}$ has been the focus of computational studies. ${ }^{12,13}$ However, the mechanism of this important reaction remains unclear. The three possible activation modes are shown in Scheme 1 (modes $\mathrm{A},{ }^{14} \mathrm{~B},{ }^{12}$ and $\mathrm{C}^{13}$ ). Pápai and co-workers suggested that this reaction proceeded by mode $\mathrm{B}$, but their mechanistic proposal was based on the relative energies of prereaction complexes; no transition states (TSs) were located. ${ }^{12}$ Subsequently, Wang and co-workers proposed that this reaction proceeded via mode $\mathrm{C}$ by locating competing TSs. ${ }^{13}$ However, activation mode B was not considered in their mechanistic work, and examination of their mode C TS shows that it actually corresponds to mode A. Neither computational study explained the origins of stereoselectivity. We have previously studied the cinchona urea-catalyzed asymmetric conjugate addition of aromatic thiols to cycloalkenones using density functional theory
(DFT) and found that the electrophile was activated by a protonated amine and that the urea binds the nucleophile by hydrogen bonding (the Brønsted acid-hydrogen bonding model). ${ }^{15}$ However, the validity of this mechanistic model in the context of cinchona thiourea catalysis was unclear given the large difference in acidity between ureas and thioureas (Figure 1) and the change in substrate.

Therefore, we have explored the mechanism and origins of stereoselectivity of Soós' cinchona thiourea-catalyzed asymmetric Michael addition of nitroalkanes to enones using DFT calculations. The reaction was found to proceed via activation mode B in full agreement with our previous work on cinchona alkaloid and cinchona urea-catalyzed conjugate additions. ${ }^{15,16}$ This result leads to the correction of the mechanistic conclusion reported by Wang and co-workers for Soós' reaction. Since the pioneering work by Rawal in $2008,{ }^{17}$ chiral squaramides have been reported to catalyze many highly asymmetric reactions. ${ }^{18-20}$ We also report DFT calculations that examine the asymmetric Michael addition of nitroalkanes to enones but catalyzed by the corresponding cinchona squaramide reported by Yang and Du in 2010 (Scheme 2). ${ }^{21}$ A common mechanism was found between these two cinchona-catalyzed reactions (mode B) despite the differences in the geometry of their hydrogen-bond-

Received: March 3, 2017

Published: March 20, 2017 
Scheme 1. Cinchona Alkaloid-Derived Thiourea-Catalyzed Asymmetric Michael Addition of Nitroalkanes to Enones ${ }^{6}$ and Possible Activation Modes

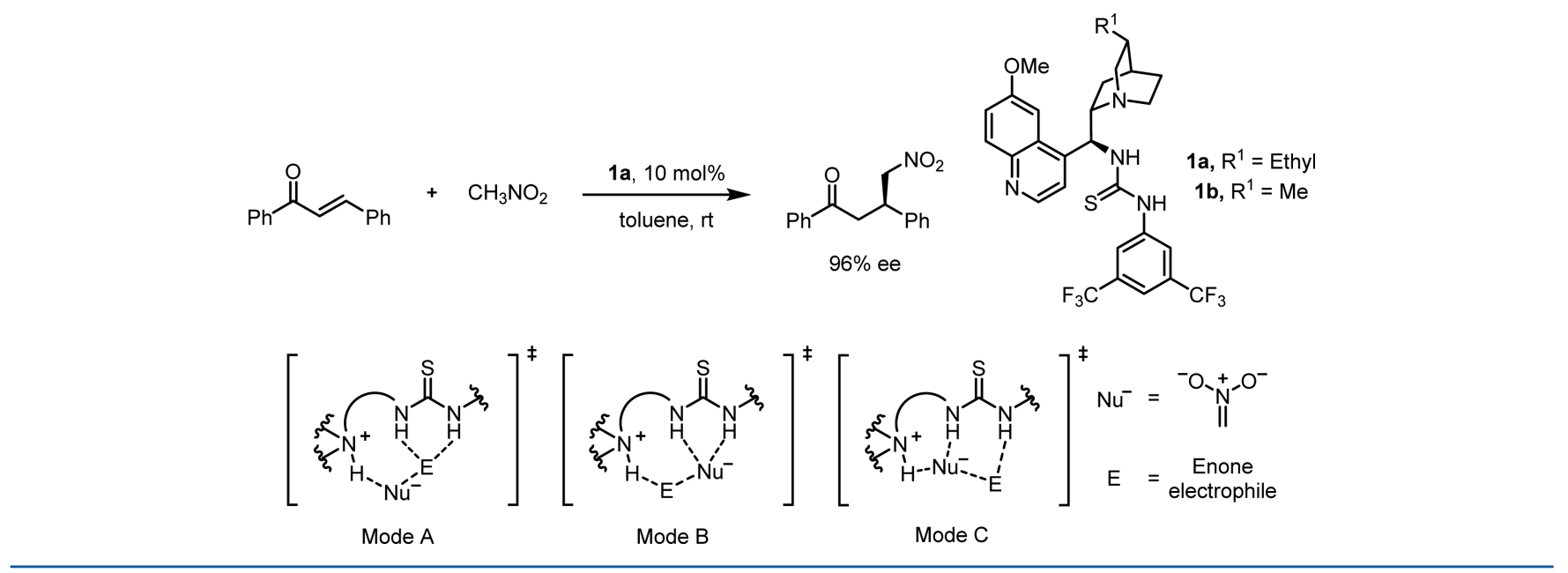

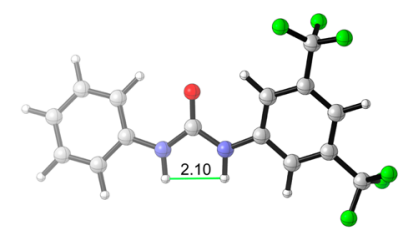<smiles>O=C(Nc1ccccc1)Nc1cc(C(F)(F)F)cc(C(F)(F)F)c1</smiles>
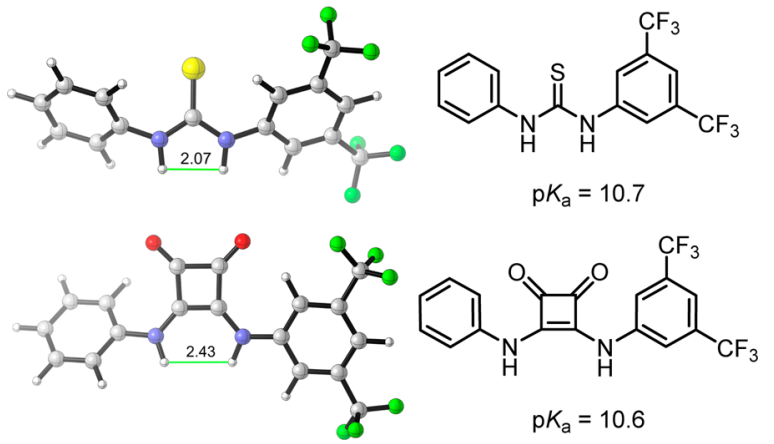

Figure 1. Optimized structures (M06-2X/6-31G(d)-IEFPCM(DMSO)) and $\mathrm{p} K_{\mathrm{a}}$ values in $\mathrm{DMSO}^{22,23}$ for model urea, thiourea, and squaramide catalysts.

donating groups (Figure 1), demonstrating the generality of this mechanistic model.

\section{RESULTS AND DISCUSSION}

In the cinchona thiourea-catalyzed asymmetric Michael addition of nitroalkanes to enones, the first step is deprotonation of the nitroalkane by the quinuclidine base which is followed by ratedetermining $\mathrm{C}-\mathrm{C}$ bond formation. ${ }^{12,13}$ Mode A-, B- and C-type pre-reaction complexes are expected to be in rapid equilibrium, and so their relative thermodynamic stabilities do not determine the preferred reaction pathway (Curtin-Hammett conditions). ${ }^{12,24}$ Therefore, we have investigated the relative stabilities of the $\mathrm{C}-\mathrm{C}$ bond-forming TSs to determine which catalyst activation mode is preferred and to explain the observed stereoselectivity. The ethyl group on the quinuclidine ring of catalyst 1a was replaced by a methyl group to simplify our calculations (catalyst $\mathbf{1 b}$, Scheme 1). ${ }^{25,26}$

Mode B TSs leading to the major and minor products via the $s$ cis and s-trans conformations of the enone are shown in Figure 2. The two catalyst conformations considered for these TSs are that seen in $\mathrm{TS}_{\text {thio }}-\mathrm{B}_{\text {cis }}$-(major) and $\mathrm{TS}_{\text {thio }}-\mathrm{B}_{\text {trans }}$-(minor) which differ only by rotation of the quinoline ring by $\sim 180^{\circ}$ (syn-open and anti-open conformations, respectively). These conformations have previously been shown to be strongly preferred over all other possibilities. ${ }^{15}$ Both conformations were considered for all TSs, the lowest energy of which is shown in Figures 2-5. Rotation of the quinoline ring's methoxy group by $\sim 180^{\circ}$ so that the methyl group is oriented away from the thiourea moiety leads to a further two possible TSs. However, these conformations were found to be disfavored by at least $2.2 \mathrm{kcal} \mathrm{mol}^{-1}$ for the synand anti-open conformations of $\mathrm{TS}_{\text {thio }}-\mathrm{B}_{\text {cis }}-$ (major) and were therefore not considered further.

The lowest energy TS was calculated to be $\mathrm{TS}_{\text {thio }}-\mathrm{B}_{\mathrm{cis}}$-(major), which leads to the major product observed experimentally (Figure 2). $\mathrm{TS}_{\text {thio }}-\mathrm{B}_{\mathrm{cis}}$-(minor) is disfavored relative to this TS due to unfavorable steric interactions between the substrate's phenyl substituent and the catalyst's quinuclidine ring. Furthermore, $\mathrm{TS}_{\text {thio }}-\mathrm{B}_{\mathrm{cis}}$-(major) is stabilized by $\pi$-stacking interactions between the substrate's phenyl group and the catalyst's aromatic ring. ${ }^{27}$ These interactions are absent in $\mathrm{TS}_{\text {thio }}{ }^{-}$ $\mathrm{B}_{\text {cis }}-($ minor $)$. $\mathrm{TS}_{\text {thio }}-\mathrm{B}_{\text {trans }}$-(major) and $\mathrm{TS}_{\text {thio }}-\mathrm{B}_{\text {trans }}-($ minor $)$ are disfavored relative to $\mathrm{TS}_{\text {thio }}-\mathrm{B}_{\text {cis }}$-(major) because they adopt the less favorable s-trans conformation of the enone. The s-cis conformation of the enone in isolation was calculated to be favored over the $s$-trans by $1.0 \mathrm{kcal} \mathrm{mol}^{-1}$. Furthermore, no $\pi$ stacking is present in these TSs.

Mode A TSs are shown in Figure 3. The two TSs adopting the $s$-cis conformation of the enone are the lowest in energy $\left(\mathrm{TS}_{\text {thio }^{-}}\right.$ $\mathrm{A}_{\text {cis }}-($ major $)$ and $\mathrm{TS}_{\text {thio }}-\mathrm{A}_{\text {cis }}-($ minor $\left.)\right)$. $\mathrm{TS}_{\text {thio }}-\mathrm{A}_{\text {trans }}-($ major $)$ and $\mathrm{TS}_{\text {thio }}-\mathrm{A}_{\text {trans }}$-(minor) are higher in energy because they adopt the less favorable s-trans enone conformation. $\mathrm{TS}_{\text {thio }}-\mathrm{A}_{\text {cis }}-($ minor) is the lowest energy TS across both activation modes that leads to the minor product. All mode A TSs are disfavored relative to $\mathrm{TS}_{\text {thio }}-\mathrm{B}_{\text {cis }}$-(major) because mode B TSs stabilize the enone's developing alkoxide to a greater extent than mode A TSs (proton transfer from the quinuclidinium ion versus hydrogen bonding from the thiourea). ${ }^{15}$ To ensure that the preference for mode $B$ over mode A was consistent across methods, we have performed three sets of additional single-point energy calculations in which either the functional, basis set, or solvent model was changed. In these additional calculations, we used the M11 functional, the 6$311 \mathrm{G}(\mathrm{d}, \mathrm{p})$ basis set, and the SMD solvent model as substitutes in turn. Mode B was still strongly preferred over mode A in all three 
Scheme 2. Cinchona Alkaloid-Derived Squaramide-Catalyzed Asymmetric Michael Addition of Nitroalkanes to Enones ${ }^{21}$ and Possible Activation Modes
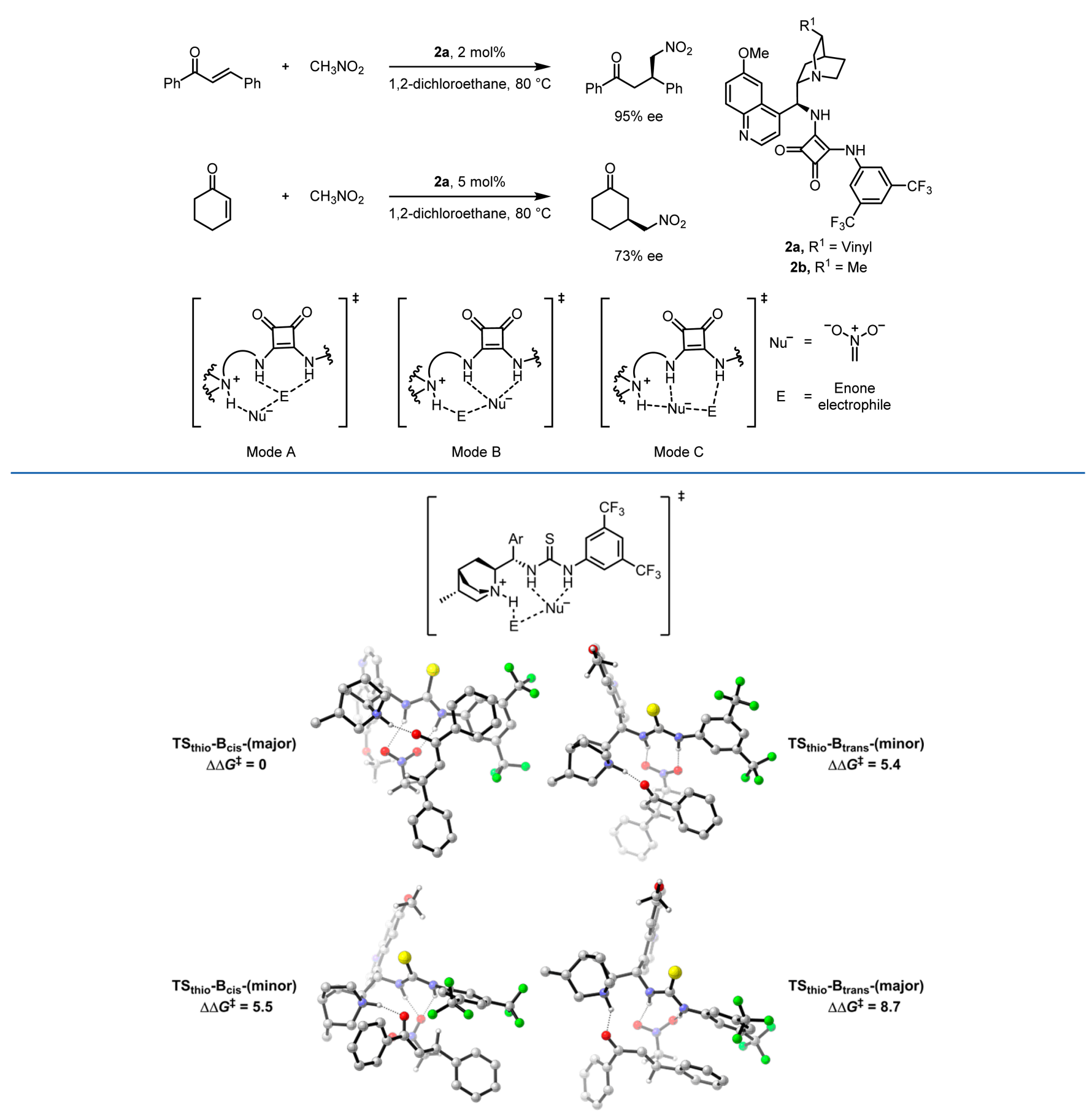

Figure 2. Mode B C-C bond-forming TSs in cinchona thiourea-catalyzed asymmetric Michael addition of nitroalkanes to enones. M06-2X/def2TZVPP-IEFPCM(toluene)//M06-2X/6-31G(d)-IEFPCM(toluene). Noncritical hydrogen atoms omitted for clarity. All energies in kcal mol ${ }^{-1}$.

cases (4.4, 4.2, and $3.5 \mathrm{kcal} \mathrm{mol}^{-1}$ respectively), adding further weight to our mechanistic conclusion.

Our attempts to locate TSs that corresponded to mode C optimized instead to mode A. This observation is in agreement with other studies that computationally investigated similar reactions. ${ }^{15,28}$ Examination of the mode C TS originally reported by Wang for this reaction shows that it actually corresponds to mode A. Therefore, we conclude that Soós' cinchona thioureacatalyzed asymmetric Michael addition of nitroalkanes to enones proceeds via activation mode $B$, a result that leads to the correction of the mechanistic conclusion reported by Wang and co-workers for this reaction.

We have also investigated the cinchona squaramide-catalyzed asymmetric Michael addition of nitroalkanes to enones (Scheme $2)^{21}$ to examine the generality of this mechanistic model and to see if the differences in the geometry of the thiourea and squaramide hydrogen-bond-donating groups (Figure 1) changes the preferred mechanism. The three lowest energy TSs are shown in Figure 4. Mode B is again favored over mode A by more than $2 \mathrm{kcal} \mathrm{mol}^{-1}\left(\mathrm{TS}_{\mathrm{sq}}-\mathrm{B}_{\mathrm{cis}}-\right.$ (major) and $\mathrm{TS}_{\mathrm{sq}}-\mathrm{A}_{\mathrm{cis}}-$ (major), 


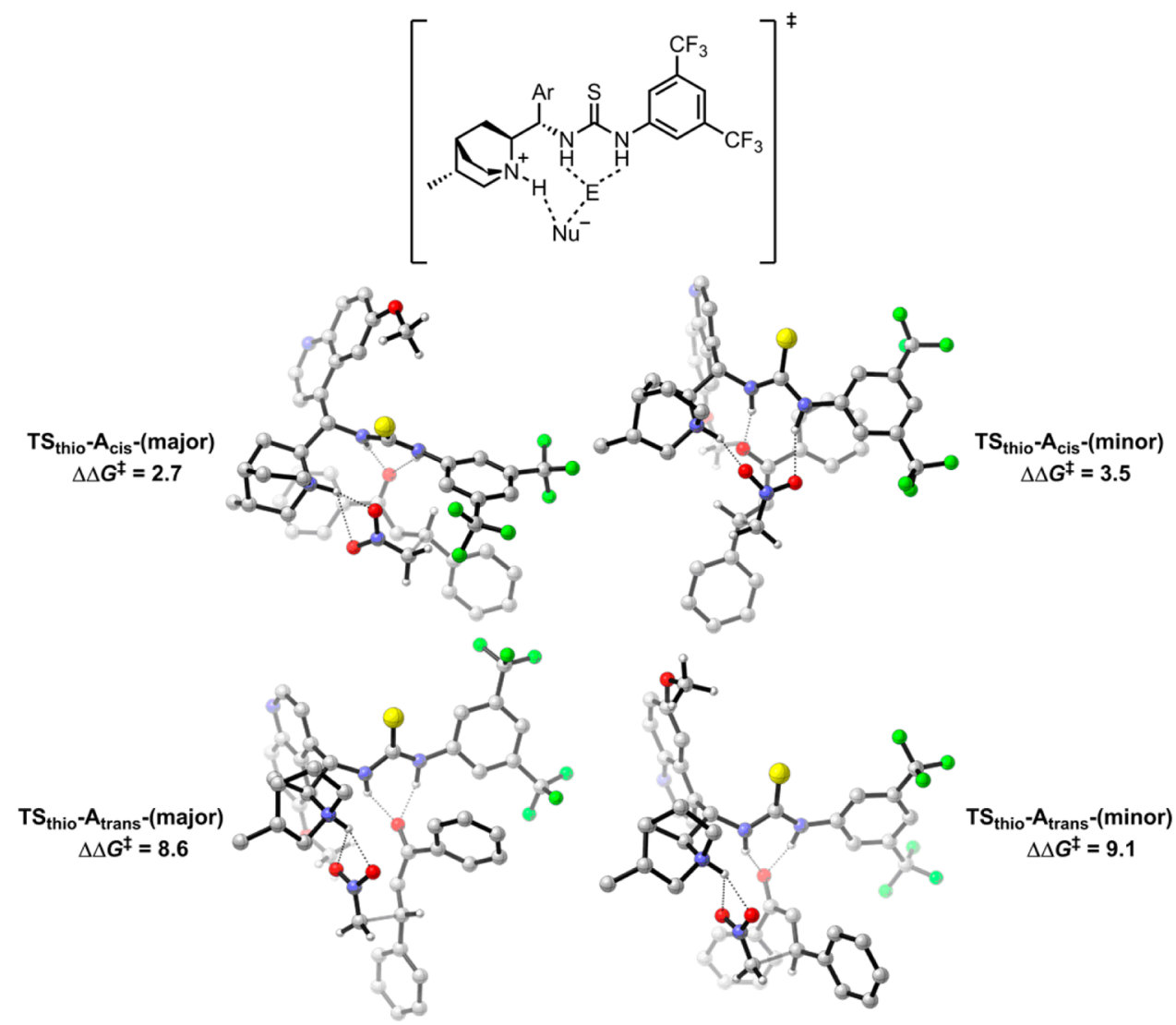

Figure 3. Mode A C-C bond-forming TSs in cinchona thiourea-catalyzed asymmetric Michael addition of nitroalkanes to enones. Free energies relative to $\mathrm{TS}_{\text {thio }}-\mathrm{B}_{\text {cis }}$-(major). M06-2X/def2-TZVPP-IEFPCM(toluene)//M06-2X/6-31G(d)-IEFPCM(toluene). Noncritical hydrogen atoms omitted for clarity. All energies in $\mathrm{kcal} \mathrm{mol}^{-1}$.
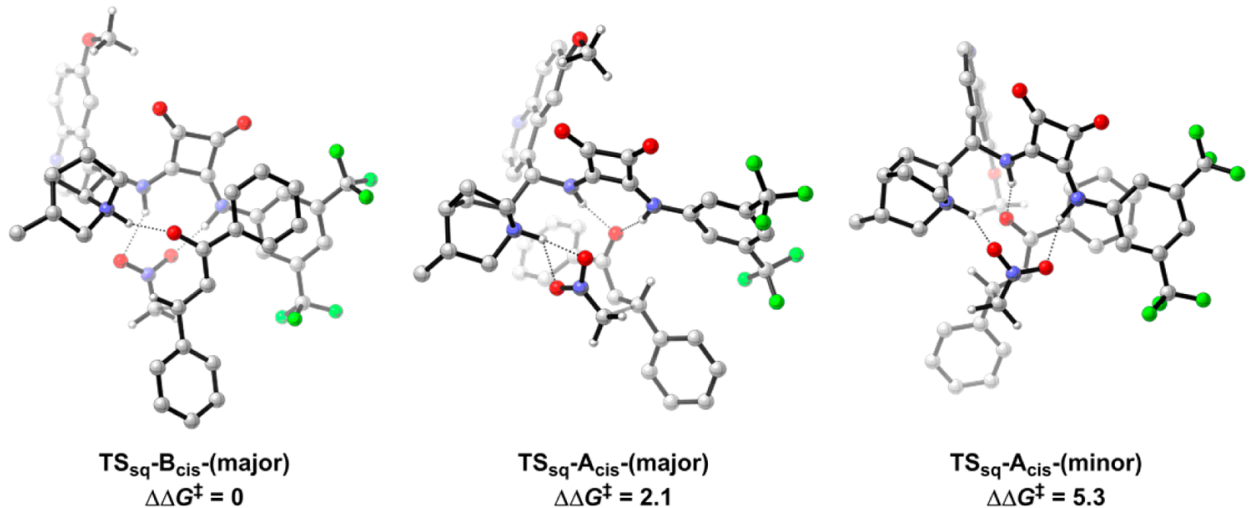

Figure 4. Three lowest energy $\mathrm{C}-\mathrm{C}$ bond-forming TSs in cinchona squaramide-catalyzed asymmetric Michael addition of nitroalkanes to enones. M062X/def2-TZVPP-IEFPCM(1,2-dichloroethane)//M06-2X/6-31G(d)-IEFPCM(1,2-dichloroethane). Noncritical hydrogen atoms omitted for clarity. All energies in $\mathrm{kcal} \mathrm{mol}^{-1}$.

respectively). $\mathrm{TS}_{\mathrm{sq}}-\mathrm{A}_{\mathrm{cis}}$-(minor) is the lowest energy TS across both activation modes that leads to the minor product, in agreement with our thiourea results. Additional transition-state conformations were generated by rotation about the nucleophile-electrophile $\mathrm{C}-\mathrm{C}$ bond-forming distance for the squaramide-catalyzed mode A reaction. However, these transition states were either found to be strongly disfavored or optimized back to the original transition state geometries. It has been shown that catalyst aggregation can lead to lower levels of enantioselectivity in cinchona-catalyzed reactions and is suggested to be the reason why the selectivity observed experimentally in the squaramide-catalyzed reaction is lower than that predicted by our calculations. ${ }^{15}$ To examine substrate generality, TSs for the squaramide-catalyzed reaction of a cyclic enone were also located (Scheme 2). Mode B was calculated to be favored over mode $\mathrm{A}$ by $2.0 \mathrm{kcal} \mathrm{mol}^{-1}\left(\mathrm{TS}_{\mathrm{sq}}-\mathrm{B}_{\mathrm{cyc}}\right.$-(major) and $\mathrm{TS}_{\mathrm{sq}}-\mathrm{A}_{\mathrm{cyc}}$-(major), respectively, Figure 5). These results further demonstrate the generality of our mechanistic model.

\section{CONCLUSIONS}

DFT calculations show that the preferred reaction pathway in Soós' cinchona thiourea-catalyzed asymmetric Michael addition of nitroalkanes to enones is activation of the electrophile by the catalyst's protonated amine and binding of the nucleophile to the 


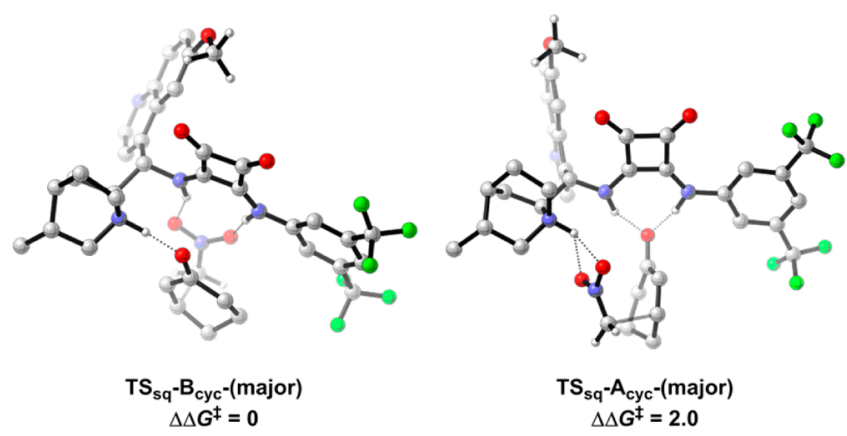

Figure 5. Comparison of activation modes in cinchona squaramidecatalyzed asymmetric Michael addition of nitroalkanes to cyclic enones. M06-2X/def2-TZVPP-IEFPCM(1,2-dichloroethane)//M06-2X/6$31 \mathrm{G}(\mathrm{d})$-IEFPCM(1,2-dichloroethane). Noncritical hydrogen atoms omitted for clarity. All energies in $\mathrm{kcal} \mathrm{mol}^{-1}$.

thiourea moiety by hydrogen bonding (mode B). This is preferred over the alternative mechanism in which the nucleophile is bound to the protonated amine and the thiourea moiety activates the electrophile by hydrogen bonding (mode A). These results lead to the correction of the mechanistic conclusion reported by Wang and co-workers for this reaction drawn as a result of their DFT calculations. The lowest energy TS leading to the minor product corresponds to mode $A$; mode $B$ TSs leading to this product are destabilized by either a steric clash with the catalyst or they adopt the less favorable s-trans enone conformation. We have also investigated the same reaction but catalyzed by the corresponding cinchona squaramide. A common mechanism was found between these two cinchonacatalyzed reactions, despite the differences in the geometry of their hydrogen-bond-donating groups, demonstrating the generality of this mechanistic model.

\section{EXPERIMENTAL SECTION}

Quantum mechanical calculations were performed using Gaussian 09 (Revision D.01). ${ }^{29}$ All geometries were optimized using the M06-2X density functional, ${ }^{30}$ the $6-31 \mathrm{G}(\mathrm{d})$ basis set and an ultrafine integration grid within the IEFPCM model. ${ }^{31}$ Single-point energies were calculated using M06- $2 \mathrm{X}$, the polarized, triple- $\zeta$ valence quality def2-TZVPP basis set of Weigend and Ahlrichs ${ }^{32}$ to minimize basis set superposition errors $^{33}$ and an ultrafine integration grid within the IEFPCM model. The resulting energies were used to correct the energies obtained from the M06-2X optimizations. ${ }^{34-36}$ The free energy corrections were calculated using Truhlar's quasiharmonic approximation ${ }^{37}$ with GoodVibes. ${ }^{38}$ Previous computational studies of cinchona catalysis with similar methods provided results in accord with experiment. ${ }^{39-41}$ Computed structures are illustrated with CYLView. ${ }^{42}$

\section{ASSOCIATED CONTENT}

\section{S Supporting Information}

The Supporting Information is available free of charge on the ACS Publications website at DOI: 10.1021/acs.joc.7b00521.

Complete list of authors for ref 29; Cartesian coordinates, energies, free energies and number of imaginary frequencies of all stationary points; and values of imaginary frequencies of all transition structures(PDF)

\section{AUTHOR INFORMATION}

\section{Corresponding Author}

*E-mail: mng26@cam.ac.uk.

ORCID

Matthew N. Grayson: 0000-0003-2116-7929

\section{Notes}

The author declares no competing financial interest.

According to the University of Cambridge data management policy, all the data used in this paper is available either in the paper or in the Supporting Information.

\section{ACKNOWLEDGMENTS}

M.N.G. thanks Girton College, Cambridge (Research Fellowship) for financial support. Part of this work was performed using the Darwin Supercomputer of the University of Cambridge High Performance Computing Service (http://www.hpc.cam.ac.uk/), provided by Dell Inc. using Strategic Research Infrastructure Funding from the Higher Education Funding Council for England and funding from the Science and Technology Facilities Council. Prof. Jonathan Goodman is thanked for his support and helpful discussions regarding this work.

\section{REFERENCES}

(1) Doyle, A. G.; Jacobsen, E. N. Chem. Rev. 2007, 107, 5713-5743.

(2) Connon, S. J. Chem. Commun. 2008, 2499-2510.

(3) Melchiorre, P. Angew. Chem., Int. Ed. 2012, 51, 9748-9770.

(4) Lam, Y.-h.; Grayson, M. N.; Holland, M. C.; Simon, A.; Houk, K. N. Acc. Chem. Res. 2016, 49, 750-762.

(5) Li, B.-J.; Jiang, L.; Liu, M.; Chen, Y.-C.; Ding, L.-S.; Wu, Y. Synlett 2005, 603-606.

(6) Vakulya, B.; Varga, S.; Csámpai, A.; Soós, T. Org. Lett. 2005, 7, 1967-1969.

(7) McCooey, S. H.; Connon, S. J. Angew. Chem., Int. Ed. 2005, 44, $6367-6370$

(8) Ye, J.; Dixon, D. J.; Hynes, P. S. Chem. Commun. 2005, 4481-4483.

(9) Yu, X.; Wang, W. Chem. - Asian J. 2008, 3, 516-532.

(10) Vetica, F.; de Figueiredo, R.; Orsini, M.; Tofani, D.; Gasperi, T. Synthesis 2015, 47, 2139-2184.

(11) Gu, Q.; You, S.-L. Chem. Sci. 2011, 2, 1519-1522.

(12) Hamza, A.; Schubert, G.; Soós, T.; Papai, I. J. Am. Chem. Soc. 2006, $128,13151-13160$.

(13) Zhu, J.-L.; Zhang, Y.; Liu, C.; Zheng, A.-M.; Wang, W. J. Org. Chem. 2012, 77, 9813-9825.

(14) Okino, T.; Hoashi, Y.; Furukawa, T.; Xu, X.; Takemoto, Y. J. Am. Chem. Soc. 2005, 127, 119-125.

(15) Grayson, M. N.; Houk, K. N. J. Am. Chem. Soc. 2016, 138, 90419044.

(16) Grayson, M. N.; Houk, K. N. J. Am. Chem. Soc. 2016, 138, 11701173.

(17) Malerich, J. P.; Hagihara, K.; Rawal, V. H. J. Am. Chem. Soc. 2008, 130, 14416-14417.

(18) Storer, R. I.; Aciro, C.; Jones, L. H. Chem. Soc. Rev. 2011, 40, 2330-2346.

(19) Lu, T.; Wheeler, S. E. Chem. - Eur. J. 2013, 19, 15141-15147.

(20) Chauhan, P.; Mahajan, S.; Kaya, U.; Hack, D.; Enders, D. Adv. Synth. Catal. 2015, 357, 253-281.

(21) Yang, W.; Du, D.-M. Org. Lett. 2010, 12, 5450-5453.

(22) Jakab, G.; Tancon, C.; Zhang, Z.; Lippert, K. M.; Schreiner, P. R. Org. Lett. 2012, 14, 1724-1727.

(23) Ni, X.; Li, X.; Wang, Z.; Cheng, J. P. Org. Lett. 2014, 16, 17861789.

(24) Seeman, J. I. Chem. Rev. 1983, 83, 83-134.

(25) Lam, Y.-h.; Houk, K. N. J. Am. Chem. Soc. 2014, 136, 9556-9559.

(26) Lam, Y.-h.; Houk, K. N. J. Am. Chem. Soc. 2015, 137, 2116-2127.

(27) Wheeler, S. E.; Houk, K. N. J. Am. Chem. Soc. 2008, 130, 1085410855 .

(28) Kótai, B.; Kardos, G.; Hamza, A.; Farkas, V.; Pápai, I.; Soós, T. Chem. - Eur. J. 2014, 20, 5631-5639.

(29) Frisch, M. J., et al. Gaussian 09; Gaussian, Inc.: Wallingford, CT, 2013.

(30) Zhao, Y.; Truhlar, D. Theor. Chem. Acc. 2008, 120, 215-241. 
(31) Tomasi, J.; Mennucci, B.; Cammi, R. Chem. Rev. 2005, 105, 2999-3093.

(32) Weigend, F.; Ahlrichs, R. Phys. Chem. Chem. Phys. 2005, 7, 32973305.

(33) Armstrong, A.; Boto, R. A.; Dingwall, P.; Contreras-García, J.; Harvey, M. J.; Mason, N. J.; Rzepa, H. S. Chem. Sci. 2014, 5, 2057-2071.

(34) Simón, L.; Goodman, J. M. Org. Biomol. Chem. 2011, 9, 689-700.

(35) Mao, X.-M.; Zhan, Z.-J.; Grayson, M. N.; Tang, M.-C.; Xu, W.; Li, Y.-Q.; Yin, W.-B.; Lin, H.-C.; Chooi, Y.-H.; Houk, K. N.; Tang, Y. J. Am. Chem. Soc. 2015, 137, 11904-11907.

(36) Rodríguez, E.; Grayson, M. N.; Asensio, A.; Barrio, P.; Houk, K. N.; Fustero, S. ACS Catal. 2016, 6, 2506-2514.

(37) Ribeiro, R. F.; Marenich, A. V.; Cramer, C. J.; Truhlar, D. G. J. Phys. Chem. B 2011, 115, 14556-14562.

(38) Funes-Ardoiz, I.; Paton, R. S. GoodVibes, v1.0.1; DOI: 10.5281/ zenodo.56091.

(39) Sengupta, A.; Sunoj, R. B. J. Org. Chem. 2012, 77, 10525-10536.

(40) Sladojevich, F.; Fuentes de Arriba, Á. L.; Ortín, I.; Yang, T.; Ferrali, A.; Paton, R. S.; Dixon, D. J. Chem. - Eur. J. 2013, 19, 1428614295.

(41) Tanriver, G.; Dedeoglu, B.; Catak, S.; Aviyente, V. Acc. Chem. Res. 2016, 49, 1250-1262.

(42) Legault, C. Y. CYLView, version 1.0b; Université de Sherbrooke: Sherbrooke, 2009; http://www.cylview.org. 